\title{
LEIA NA MINHA CAMISA - COMUNICAÇÃO, CONSUMO E SUBVERSÃO DE SENTIDO DE MARCAS ABSOLUTAS
}

\author{
IRENE CARBALLIDO
}




\section{LEIA NA MINHA CAMISA - COMUNICAÇÃO, CONSUMO E SUBVERSÃO DE SENTIDO DE MARCAS ABSOLUTAS}

Resumo: Artigo trata da produção de sentido feita pelo micro discurso da publicidade: o nome da marca. As mensagens subvertidas veiculadas em camisas mostram que o processo de produção de sentido do nome da marca é desvendado quando destoa pela sintaxe do ready-made e do desvio. E destoa na dimensão mais ideológica da linguagem, a conotação. Com seu conteúdo bem -humorado a subversão de marcas traz reflexões sobre o universo da produção sentido em torno da mercadoria.

Palavras-chave: comunicação; consume; micro-discurso; marca; subversão

LEA EN MI CAMISA - COMUNICACIÓN, CONSUMO Y SUBVERSIÓN DEL SENTIDO DE LAS MARCAS ABSOLUTAS

Resumen: El artículo és sobre la producción de sentido hecha por el micro-discurso de la publicidade: el nombre de la marca. Los mensagens subvertidos de las camisas enseñam que el processo de producción de sentido del nombre de la marca és desvendado pela sintaxe del ready-made y del desvio. Destoa en la dimensión más ideológica del linguage, la conotação. El contenido chistoso de la subversión trae reflexiones sobre el universo de la producción de sentido de la mercancia.

Palabras-clave: comunicacción; consume; micro-discurso; marca; subversión

READ ON MY SHIRT - COMMUNICATION, CONSUMER AND SUBVERSION OF MEANING IN ABSOLUTE BRANDS

Abstract: Article is about the production of meaning made by the micro discourse in advertisement: the name of the brand. The subverted messages displayed in shirts shows that the process of production of meaning of the name in the brand is unveiled when it differs from the deviation. It also differs in the most ideological dimension of the language, the connotation. With its humorous content, it brings out thoughts about the universe of the production de meaning of the products.

Keywords: communication; consumer; micro discourse; brand; subversion 
Eu etiqueta. Em minha calça está grudado um nome, que não é meu de batismo ou de cartório. Um nome...estranho. Meu blusão traz lembrete de bebida, que jamais pus na boca, nessa vida. Em minha camiseta, a marca de cigarro, que não fumo, até hoje não fumei...Meu isso, meu aquilo. Desde a cabeça ao bico dos sapatos. São mensagens, letras falantes, gritos visuais, ordens de uso, abuso, reincidências, costume, hábito, permanência, indispensabilidade e fazem de mim homem-anúncio itinerante. (Drummond de Andrade, 1984,p.85)

\section{INTRODUÇÃO}

Os estudos sobre a produção de sentido dos objetos vêm se ampliando. Uma das formas de se entender essa produção é estudar como operam os discursos do consumo. Entre esses discursos, destacamos o da marca, que, como aponta Drummond, faz o "homem-anúncio itinerante".

Pensando um museu para a globalização, Garcia Canclini (2008) sugere que se alguém chegasse com um logotipo na camisa, que a entregasse, como dando parte de seu corpo usado para a publicidade. O que sinaliza a marca estampada nessas camisas? Como elas se tornaram meio, com mensagens?

A partir dos anos 1950, a t-shirt ganha notoriedade, passando de roupa "de baixo" à "roupa de cima", tornando-se símbolo da juventude. O logotipo escondido na gola das camisas até os anos 1970, passa à ostentação e se transforma em acessório de moda, transformando o sujeito em "mini-cartaz" (KLEIN,2002).

O nome dado à marca é a primeira operação simbólica sobre a mercadoria, transportando-a do domínio da produção, anônima, para o domínio do consumo. Nessa operação, efetuada pela publicidade e sua magia, o produto ganha, além do nome, identidade e personalidade (ROCHA,1995). A subversão das marcas se dá sobre o nome dentro das marcas. O objeto deste artigo, então, são camisas com logotipos parodiados de marcas absolutas, ou seja, marcas com notoriedade, presença constante de sua comunicação no espaço midiátiCO (CHETOCHINE,1999). É a produção dessa mensagem parodiada, consumida como objeto de contestação ante a ostentação, que iremos analisar e contribuir com o suposto museu de Garcia Canclini.

\section{A CULTURA DO CONSUMO}

Os estudos sobre o consumo, sob a perspectiva da cultura, o posicionam 
como algo ativo e constante, estruturando valores que se realizam na esfera da vida cotidiana. Garcia Canclini (1999) salienta que os indivíduos usam os bens para tornar visível uma classificação de pessoas e eventos. Entende o consumo como algo mais que o simples exercício de caprichos. Para ele, "consumir é participar de um cenário social de disputas por aquilo que a sociedade produz e pelos modos de usá-los" (GARCIA CANCLINI,1999,p.78). Para Douglas e Isherwood (2006), o consumo é parte visível da cultura, comunica o estilo de vida das pessoas, portadoras de bens que, por sua vez, são portadores de significados compartilhados, ligando bens a contextos e relações sociais.

O consumo é como um código, e através deste código são traduzidas muitas de nossas relações sociais. Ainda mais: este código, ao traduzir relações sociais, permite classificar coisas e pessoas, produtos e serviços, indivíduos e grupos. A comunicação de massa realiza a dimensão ampliada deste código, fazendo com que nos socializemos para o consumo de forma semelhante (DOUGLAS;ISHERWOOD,2006,p.16)

Os autores veêm o consumo enquanto fluxo de informação, integrando as pessoas num mundo social inteligível. Sob essa perspectiva, o significado dos bens reflete a própria ordem social e esse significado é usado nas práticas cotidianas para construir relações sociais.

A percepção de Baudrillard (1969) de que imagens e signos, e não a própria mercadoria, ou as relações sociais, é que conferem conteúdo simbólico aos objetos, está no outro lado da linha do entendimento do significado dos objetos. Para Baudrillard, os significados das mercadorias derivam inteiramente de sua posição relacional nos códigos sociais. O signo é autônomo em relação às determinações sociais. Não tem referente, se auto referencia. É relacional dentro dos códigos, sem externalidade com finalidades ou necessidades. Os códigos passam a dominar a produção e o consumo, estruturando a realidade. Signos, mídia e imagens substituem as interações reais. O vínculo social é criado pela lógica do signo. Ela domina a constituição da realidade. Para Baudrillard, a cultura do consumo é de uma passividade cada vez maior, uma absorção inócua de signos e significados, onde o sujeito está entediado e indiferente. "O signo consumível não se refere a uma sequência histórica real, e sim a uma sacola cheia de estilos ou imagens equivalentes e contemporâneos que significam e competem entre si" (BAUDRILLARD,1969,p.191). Para este autor, consumimos apenas signos e não coisas 
Para Douglas \& Isherwood, o significado dos objetos é definido nas relações sociais. Para Baudrillard, o signo é inteiramente independente, eles se relacionam entre eles, não têm relação com a mercadoria. Sob essas duas perspectivas, como a subversão de sentido das marcas entra no mundo dos signos para travar uma luta no campo simbólico? Se os códigos passam a dominar a produção e o consume, é sob a forma de código que pode haver uma subversão? Se o signo flutua livre da mercadoria e o domínio social não advém do referente e sim do signo, como o signo subvertido participa com sua autonomia de signo, entre os signos absolutos?

Slater (2002) nos traz uma visão ampliada desses aspectos. Para o autor, o consumo não é determinado por estruturas onipotentes de classificação social nem socialmente irrestrito e indeterminado. A reprodução social é transferida da cultura tradicional para o mercado de bens e trabalho. A relação entre sujeito e objeto é dialética e interpenetrante. $O$ sujeito faz o objeto e o objeto faz o sujeito. E vai mais além. Para ele, o consumo é um campo de contestação social, onde todos os objetos de consumo são significativos, porque transmitem mensagens. "Ao consumir reproduzimos (sustentamos, desenvolvemos, defendemos, contestamos, imaginamos, rejeitamos) modos de vida específicos, culturalmente significativos" (SLATER,2002,p.14). Para ele, o consumo é uma prática cotidiana em que os agentes sociais usam os recursos culturais (linguagens, imagens e objetos) para atender as suas necessidades. É imprescindível ressaltar que, para o autor, isso envolve necessariamente "reinterpretações, modificações, transgressões e pode ser usado para questionar culturalmente ou reproduzir culturalmente a ordem social" (SLATER,2002,p.146). E, sobretudo, que os objetos mais triviais constituem a estrutura de uma vida significativa e vinculam o mundo íntimo aos grandes campos de contestação social. Dito isso, nossa proposta de análise de camisas com marcas subvertidas se fundamenta. Afinal, que objeto mais trivial e impregnado de sentidos há na vida cotidiana, que uma t-shirt? Vejamos.

\section{A MATERIALIDADE DA T-SHIRT}

Ela surgiu na antiguidade para proteger da transpiração e do frio. Durante séculos, foi usada como roupa íntima, "de baixo". Segundo Baudot (2002), a t-shirt começa a aparecer como roupa "de cima", discretamente, com os sol- 
dados do exército e fazendeiros. Nos anos 50, tem-se notícia da primeira aparição na mídia: Marlon Brando em "Um Bonde Chamado Desejo" e de forma mais sensual, bem mais justa e tão suada quanto a dos soldados e fazendeiros. Quando Brando e Dean (Figuras1 e 2) transformam midiaticamente a roupa de baixo em roupa de cima, trazem com ela, através do cinema, uma presença sensual e uma mensagem (GUMBRECHET,1998).

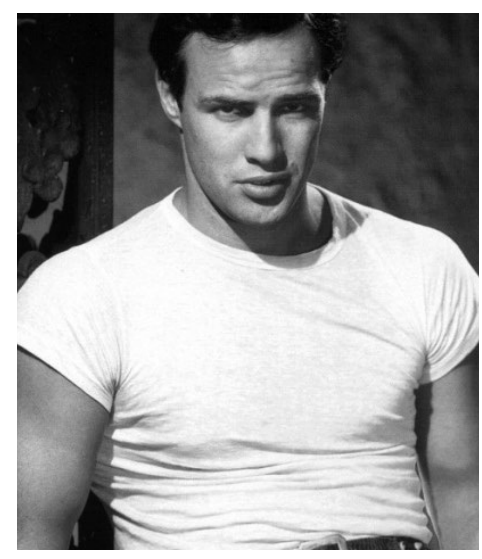

Figura 1

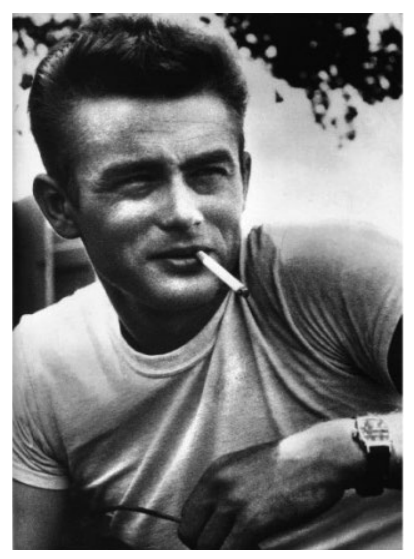

Figura 2

A camisa vai se materializar mini-cartaz nos anos 60, pelos hippies que as usam para estampar mensagens pacíficas. A partir de então, a t-shirt conquista seu espaço definitivo como peça de roupa universal e símbolo de auto-expressão.

Segundo Baitello (2010), existem 3 tipos de mediações: Meios primários: do próprio corpo. Gestos, aparência e odores são exemplos. Meios secundários: os corpos deixam marcas sobre outros suportes. Nos pictogramas, ideogramas e alfabetos. E por fim, os meios terciários, que surgem com a eletricidade, telefone, rádio, televisão e computador. "Tudo aquilo que serve de veiculador de mensagens passa a ser mídia, desde a escrita e todas as suas infindáveis manifestações até a roupa e a moda, as pinturas sobre o corpo e fora dele" (BAITELLO,2010, p.64).

O meio t-shirt então é mídia secundária. Esse mini-cartaz, que nos tornamos ao vestir uma blusa com uma mensagem ou marca estampada, é meio e também mensagem. Para McLuhan, "o efeito de um meio se torna mais forte e intenso justamente porque o seu “conteúdo" é um outro meio" (MCLUHAN,1995,p.33). Nessa perspectiva, temos uma mídia veiculada no corpo, uma mídia em movimento. Um meio que transmite uma mensagem e que transmite uma mensagem como meio. $E$, sendo símbolo de subversão juvenil, também transmite uma mensagem sobre o sujeito. Então, como a marca, com suas “ordens de uso" ou 
as camisas com marcas subvertidas de sentido se fazem presentes neste meio e nos diversos aspectos da vida cotidiana? Prossigamos.

\section{A CULTURA DA MARCA}

Segundo Fontenelle (2002), a marca é representativa de um capitalismo de imagens, e é preciso apreender a dimensão desse fenômeno e saber qual o papel que ela desempenha no consumo. Como ressalva Slater (2002), a cultura do consumo não é só de massa: o marketing e a publicidade são anteriores à produção em massa, pela necessidade humana de personalizar o impessoal.

Sim, a existência de marcas não é recente. Segundo (CHEVALIER; MAZZALOVO,2007), vem desde a Antiguidade com nomes em tijolos e animais "marcados". Na Idade Média, os escudos e selos dos reis também eram marcas, assim como, já figuravam em barris de whisky. Sempre associando o "proprietário" ao seu símbolo. Em sua essência, portanto, a marca serve para distinguir. Esse processo se intensificou com a aceleração do processo produtivo. No século $\mathrm{XIX}$, o mercado foi inundado por produtos uniformes produzidos em massa, quase indistinguíveis. A primeira tarefa era dar nomes a bens genéricos como açúcar e trigo, por exemplo, retirados de barris (Klein,2002).Esses nomes eram colocados para dar familiaridade e superar o anonimato dos bens embalados. Os nomes e marcas passaram a substituir o lojista que antes pesava os alimentos para os clientes. Daí os nomes de famílias, os chamados patronímicos, "ou de personalidades familiares, como Dr. Brown, Uncle Bens, Campbells, Heinz e Quaker" (KLEIN,2002,p.30).

A medida que cada vez mais fabricantes atingiam esse padrão, esses valores foram perdendo força como diferenciadores. Tanto Klein (2002) quanto Fontenelle (2002) apontam que a fase das marcas como a conhecemos hoje se inicia nos anos 1950 com a explosão de produtos "iguais" fabricados por empresas diferentes, tornando-se necessário criar uma imagem de marca como elemento de diferenciação, processo operado pela publicidade através do totemismo (ROCHA, 1995). É quando o capitalismo começa a se voltar para a importância do desenvolvimento de signos através da publicidade e esta passa a ser parte importante da indústria cultural. O processo de construção da marca passou a ser mais racional e sistematizado: o valor depende da identificação de um padrão. "Quem cria novos padrões, ou seja, novas marcas, pode criar 
novos mercados ou conquistar os já existentes"(FONTENELLE,2002,p.78). Na produção constante de novos produtos e serviços, a marca assume uma importância competitiva crucial. Ela entra com a força de um padrão sedimentado no mercado, garantindo segurança ao consumidor.

Há um universo habitado por objetos produzidos/compartilhados em grande escala, são eles que constituem nossa paisagem, mobiliando nosso meio ambiente. As corporações transnacionais, com seus produtos mundializados e suas marcas facilmente identificáveis, balizam o espaço mundial. As marcas mapeiam nossa familiaridade(ORTIZ,1994,p.107)

A marca é o estabelecimento do padrão, do que é familiar. Atua na nossa busca da familiaridade em tudo que o nos rodeia. Segundo Ortiz, para se "localizar", o homem preenche o vazio de sua existência com a presença de objetos familiares. "Nos pontos mais distantes nos deparamos com nomes conhecidos como Sony, Ford, Mitsubitshi, Phillips, Renault, Volkswagen. "Daí ao contemplá-los, esta sensação de familiaridade nos invade” (ORTIZ,1991,p.126). Como a marca se utiliza de elementos como a familiaridade e a distinção intrínsecas a sua condição? Como opera seu fetichismo?

\section{A MARCA COMO DISTINÇÃO}

"Ela não quer vestir nada sem um nome" diz uma mãe na loja. Este é um dos exemplos de Klein (2002) para ressaltar o poder que a marca adquiriu. Até os anos 1970, os logotipos ficavam escondidos. Garcia Canclini também se refere a esse fenômeno da exposição das marcas sobre o vestuário:

Originalmente, colocava-se nos produtos para que soubesse qual a fábrica os tinha produzido e se pudesse inferir sua qualidade. Nas calças, saias e camisas era colocada num lugar oculto e acompanhada pelo nome do país de procedência. Em vez de colocar a etiqueta abaixo da gola, ela começou a ser exibida com letras gigantescas, deformadas, abreviando as palavras, por toda a largura do suéter ou camiseta (GARCIA CANCLINI, 2008, p.64)

Foi Benjamin (1985) quem nos mostrou como as formas de produção das imagens mudaram. A "era da reprodutibilidade técnica" mudou radicalmente a crença na aura: aquela figura singular, composta de elementos espaciais 
temporais "aparição única de uma coisa distante, por mais perto que ela esteja” (BENJAMIM,1985,p.170).

Para Fontenelle (2002), a marca é um meme (replicador que adota a mente como seu habitat) poderoso, está na mente independente de você. "Ela se autonomiza a tal ponto que atinge este estado de poder de significar a si mesma através de seu próprio nome" (FONTENELLE, 2002, p.274). Para a autora, a análise da marca nos permite compreender como se processou a "perda da aura" nas imagens contemporâneas e como, paradoxalmente, "a própria marca emerge com uma aura de segunda natureza, elevando-se a categoria de fetiche" (FONTENELLE,2002, p.23). Sob essa perpectiva, seguiremos nossa análise.

O consumo é um meio privilegiado para negociar a identidade e o status numa sociedade pós-tradicional. A aparência que construímos sobre nosso corpo nos identifica e distingue, pois, "quando selecionamos os bens e nos apropriamos deles, definimos o que consideramos publicamente valioso, bem como o modo como nos integramos e nos distinguimos"(GARCIA CANCLINI,1999, p.45). As marcas participam dessa distinção.

Para Slater (2002), a importância da obra de Bourdieu está em não deixar que a cultura do consumo se desintegre em sistemas de símbolos ou reduzí-la a uma ordem social preexistente. O termo chave para o processo social na cultura do consumo é a distinção, que não implica só a diferença, mas a hierarquia. Para Slater, a perspectiva de Bourdieu a partir do conceito de habitus, é de que gostos classificam quem o classifica. Assim, segundo o autor, o significado dos bens advém do seu papel como indicador de status social, símbolo, que mostra a participação ou a aspiração de participar de grupos. Os indicadores de status, nesta perspectiva, são os bens de consumo e o modo como eles são consumidos. Seu valor está na capacidade de indicar posição social.

Portanto, nos parece que, as camisas que estampam marcas absolutas carregam a aura da marca, essa aura de segunda ordem, da "presença de uma ausência" (FLUSSER,2007). A marca absoluta, estampada na camisa, formando um mini-cartaz, é usada como elemento de distinção. Como se o sujeito fosse, ele mesmo, um "produto" a ser distinguido dos demais "produtos". Como se o sujeito fosse, ele mesmo, um signo "diferenciado" pronto para ser colocado dentro da sacola de Baudrillard e ser, ele mesmo, portador da aura de segunda 
natuteza, a presença de uma ausência (Figura 3). Por outro lado, a subversão de sentido de marcas absolutas também atua como distinção. Quem usa uma camisa com uma marca modificada, também classifica "a si próprio" e se distingue.

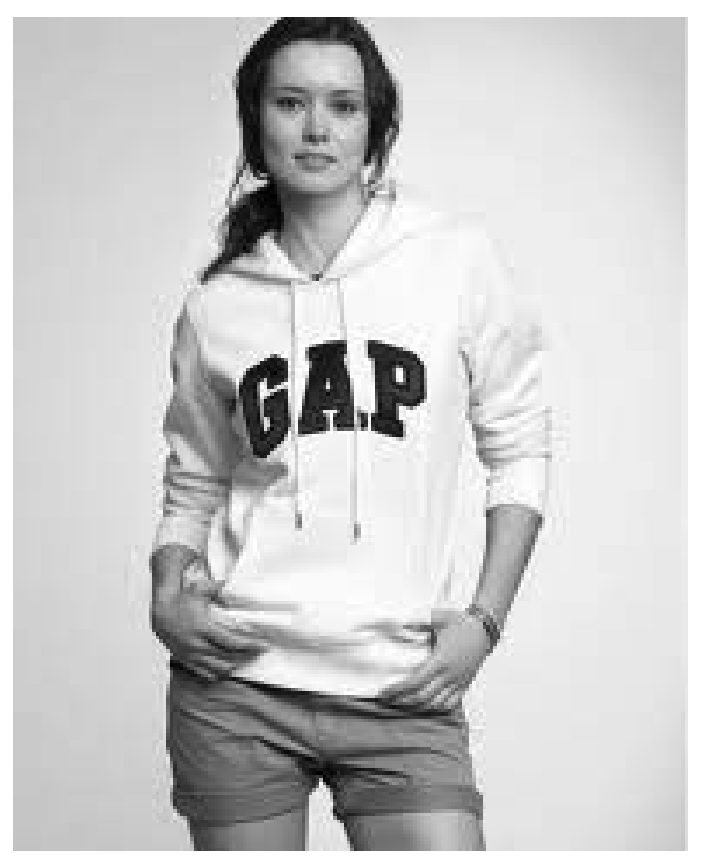

Figura 3

\section{TOTEMISMO E PUBLICIDADE}

$\mathrm{Na}$ indústria cultural, fenômenos como publicidade se configuram da maior importância pois refletem e explicitam certas características da sociedade. Para Rocha (1995), o anúncio deve ser lido como um mito. Destaca-se nessa narrativa, o que ele denomina de "operação totêmica":

Pela publicidade um produto múltiplo e impessoal se transforma em algo único, nomeado, particular, próprio para cada consumidor. Através dela os domínios "nobres" "eróticos" "misteriosos" de nossa sociedade se articulam com produtos cujas etapas de fabricação não são segredos, são claras e observáveis. Por muitas maneiras, tal como um sistema de classificações totêmico, os anúncios desfazem contradições de diferentes níveis. (ROCHA,1995, p.61)

Para o autor, a publicidade está entre os domínios fundamentais do circuito econômico: o domínio da produção e o domínio do consumo. Ela faz a 
interação entre esses dois domínios. "Pela publicidade é que se transforma o domínio da produção - onde os produtos são indiferenciados, múltiplo seriados e anônimos - no domínio do consumo onde o produto tem nome, nobreza, mistério e vida" (ROCHA,1995, p.62).

Outros autores como Slater (2002) salientam esse aspecto ideológico da publicidade sobre as mercadorias. "Para religar consumidor e produto no interior desse espaço mediado, ambos precisam ser personificados de novo, ter um significado, e um significado que os una" (SLATER,2002, p.38). Para Slater, esse processo é fetichista porque envolve "a projeção ou externalização de faculdades humanas e valores humanos na imagem de um 'Deus' ou totem independente - o mundo dos objetos é dotado de faculdades, propriedades, valores e significados intrínsecos" (2002, p.112).

Para Appadurai (2010), as imagens de sociabilidade, pertencimento, poder, distinção e intimidade colocadas na publicidade visam a transformação do consumidor a tal ponto que a mercadoria que está sendo vendida fica em segundo plano. Essa dupla inversão das relações entre pessoas e coisas é vista por Appadurai como um movimento cultural crucial do capitalismo. Silvestone (2005) também vê esse processo como um jogo contínuo de produtos e significados, deslocando a atenção para longe da "dor da extração ou da manufatura" e em direção ao objeto, sua imagem e sua apropriação no uso. Assim, a publicidade e o marketing acrescentam significados a objetos funcionais.

Para Rocha "o produto e a situação dentro de cada e todo anúncio classificam pessoas e atitudes ao classificarem a si próprios" (1995,p.60). Vê a operação totêmica como um esquecimento do processo pelo qual passou o produto, como se sua existência anterior fosse pagã e agora com a magia da publicidade ele passa ao convívio humano.

A subversão de sentido opera com os mesmos elementos da magia e do fetiche. Parece fazer um tipo de operação totêmica às avessas, como se retornasse a marca de novo para o lado da produção. Sob a forma de signo, agora ressignificado, expõe "a dor da extração e da manufatura". Assim, pela subversão, retoma o aspecto pagão das marcas (Figuras 4 e 5). Quando lemos Evil e não Levis ou quando lemos Starfucks e não Starbucks, muda-se o sentido estabelecido e absoluto, e um tipo de denúncia é feita. Ou quando lemos Disney War e não Disney World, DASPU como DASLU, é o momento em que o 
novo sentido, que salta da imagem da marca, reivindica seu lugar comunicativo, revela e contesta o aspecto de mito da marca, e que fez o nome refém de camadas e camadas de identidade e personalidade colocadas pela publicidade.

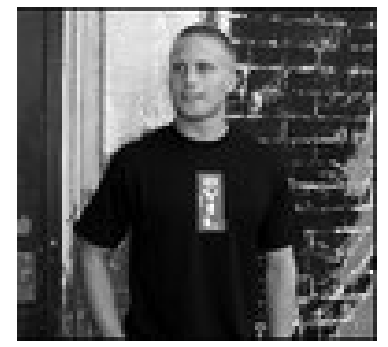

Figura 4

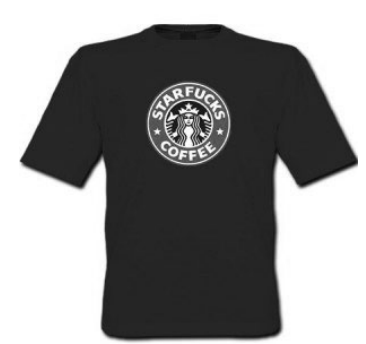

Figura 5

\section{NO NOME DENTRO DA MARCA}

Tanto para Fontenelle, quanto para Klein (2002), marca e publicidade não representam o mesmo processo, para ambas, o consumo de marcas não se confunde com o consumo de publicidade. É anterior a ela. Portanto, faz-se cada vez mais necessário ampliar a análise dos elementos persuasivos dos diversos dêiticos em torno de uma marca, e seu nome é um deles. Se é através do consumo que nos relacionamos, é através dos nomes que damos significado ao que nos rodeia e fazemos a realidade da vida cotidiana, o nome de um objeto está impregnado de significações e necessita ser desvendado. "O desfrute do consumo físico é só uma parte do serviço prestado pelos bens: a outra parte é o desfrute do compartilhamento de símbolos. Essas alegrias de compartilhar nomes são recompensas de um longo investimento de tempo e de atenção e também de dinheiro (DOUGLAS;ISHERWOOD, 2004, p.125).

Rocha (1995) defende que o anúncio publicitário é um fato cultural e tem um significado que é de domínio público. Pode ser lido como um mito, uma narrativa. Podemos dizer, que a marca é também um fato cultural. Uma micro-narrativa, um mito. Pode-se através dos nomes das marcas, levantar os olhos para um universo de significações, um olhar sobre o micro discurso do consumo.

A análise de Carrascoza (2003) sobre textos, títulos e slogans confere base teórica sobre as técnicas persuasivas da publicidade. Textos de 5 linhas, títulos de 2 linhas e slogans de 3 palavras, já dão o indicativo de que há dêiticos cada vez mais concisos. No composto comunicativo, o naming (RODRIGUES,2011), ou o nome da marca exerce a função persuasiva mais mi- 
nimalista, ainda mais reduzida desses códigos: uma só palavra. Sobre esse fenômeno ressalta Baudrillard:

De tal maneira se leva a cabo a restruturação psicológica do consumidor em uma palavra: Phillips, General Motors, capaz de resumir de uma só vez, uma diversidade de objetos e múltiplos significados difusos. Esta linguagem é, sem duvida, a mais pobre de todas: carregada de significações e carente de sentido (BAUDRILLARD,1969, p. 217)

Em meio a essas características históricas e culturais, o nome da marca ganha seus contornos próprios. Nosso objetivo é deslocar o nome de dentro da marca, pois a marca é vista como uma imagem, "sua força está, exatamente, em sua capacidade de criar uma diferença como imagem, embora seja o nome da marca que sustenta essas imagens, e só por meio dele poderemos compreender o funcionamento do fetichismo" (FONTENELLE,2002, p.23).

Quando se consome uma determinada marca o que se busca é algo já definido anteriormente por ela. Mesmo que uma marca faça pequenas mudanças em função de mudanças sociais, ainda persiste o seu nome. "Não é a imagem, mas o nome da marca que importa, já que as imagens se deslocam o tempo todo em torno do nome, que é fixo" (FONTENELLE,2002, p.25). A marca precisa de um lugar de ordem para continuar operando em meio às oscilações sociais. O sentido de permanência é dado pelo nome. Para Fontenelle, a marca é oca, o nome é padrão. A marca é sua flexibilidade, dada pela personalidade e identidade, que a publicidade vai alimentando. A marca nada mais é do que um nome que você tem na mente, já que esse nome se constitue a partir de algum significado.

Interessante perceber, que a subversão de sentido se dá no interior da marca, em seu padrão estabelecido. O signo associado ao produto é subvertido nos elementos discursivos que o constituem, na palavra, em seu significante e significado.

Para Slater, a semiótica de Saussure pode mostrar o "modus operandi" do fetichismo. O seu maior ganho está em reconhecer que as coisas não têm significados inerentes: os significados e as coisas são organizados socialmente. "A semiótica pode falar sobre a forma pela qual as diferentes organizações das coisas e seus significados surgem dos sistemas de significados" (SLATER,2002, p.137). A unidade linguística básica, o signo, é dividido em significante (a palavra que designa o objeto), o significado (o quer dizer). O signo estabelece uma 
relação entre a noção de um objeto qualquer (o significado) e sua representação (significante), exprime a associação de uma expressão e seu conteúdo, a esta ação do signo se chama de significação (COHN,1987). Para Barthes(1993) a denotação é a relação direta entre significante e significado (sistema primário) flor é flor. Na conotação - não há relação entre significante e significado (que se constrói sobre o primário) flor pode ser paz ( $\mathrm{COHN}, 1987)$.

Hall (2003) não faz distinção entre denotação e conotação. Para ele, muito poucas vezes os signos organizados em um discurso significarão somente seus sentidos literais. Os signos parecem adquirir seu valor ideológico pleno no nível dos sentidos associativos, ou seja, no nível da conotação. Para Hall, é no nível conotativo do signo que as ideologias alteram e transformam sua significação. Isto não quer dizer que a denotação ou o sentido literal esteja fora da ideologia. Ele está fortemente fixado, tanto que se tornou natural. O signo arbitrário é produto, não da natureza, mas de uma convenção, e o convencionalismo dos discursos requer a intervenção e o apoio dos códigos.

Certos códigos podem, claro, ser tão amplamente distribuídos em uma cultura ou comunidade de linguagem específica, e serem aprendidos tão cedo, que aparentam não terem sido construídos, o efeito de uma articulação entre signo e referente, mas serem dados "naturalmente" (HALL,2003, p.7)

As marcas absolutas aparentam essa característica, de signo "natural". Estão aí e vão estar aí depois de nós, nem parece que foram criadas e "isso produz o efeito ideológico de encobrir as práticas de codificação presentes" (HALL,2003,p.7). Podemos dizer que as marcas absolutas são denotação pura. A subversão de sentido as faz aparecer e saltar da marca, revelando o mito. $O$ que parecia "escondido" dentro da imagem, ao ser subvertido, reivindica um lugar. O significante externaliza essa subversão e sob ações de significação, operadas pela conotação, se dá a subversão de sentido. Temos que reconhecer tanto o significado da referência (marca), quanto também o significado da subversão (conotação). Por exemplo, reconhecemos a marca e nome Puma (tênis e animal). Mas se não reconhecemos o significado da subversão do significante Tuna (atum em espanhol), se não o decodificamos como um peixe, a subversão sobre a marca Puma, não faz sentido (Figura 6). 


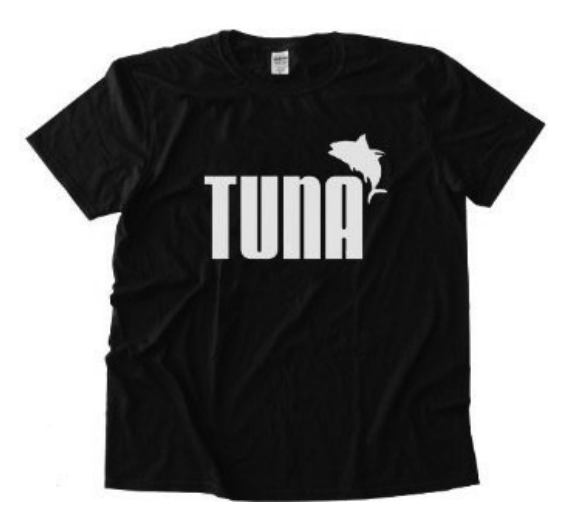

Figura 6

\section{READY-MADE, JOGO E HUMOR SOBRE A MARCA ABSOLUTA}

Para Nunes (2011) os sistemas semióticos verbais, orais, impressos e cênicos participam da semiosfera. Dentro dessa semiosfera, os textos devem ser vistos como estruturas contraditórias e ambíguas e não como estruturas objetivas e coerentes, pois ninguém pode determinar o significado que nunca é fixo, os significados são sempre adiados, dependentes de outro significado. "Nenhum sistema de signo tem sua significação acabada, conferindo à cultura dinamismo, assegurando a ação do signo ad infinitum, construindo novas informações que serão traduzidas, ou modelizadas, em linguagens, textos, códigos, em processo contínuo (NUNES,2011, p.19)

Os signos misturam-se criando sintaxes (relações entre os signos), semânticas (relação entre os signos com o que ele significa) e pragmáticas (relações dos signos com seu usuário (NUNES,2011). Essa sintaxe está presente também na publicidade. É o que Carrascoza aponta como ready-made, fazendo menção a Duchamp, e sua a técnica criativa que consiste "em separar o objeto do seu contexto original, alterando seu significado"(CARRASCOZA,2008,p.79). Poderíamos dizer que a subversão de sentido das marcas é um ready-made. Vejamos: a marca absoluta é um estereótipo, elemento do repertório do público, local e global. O nome, sendo padrão, é familiar, conhecido. É sobre o nome que é feito o ready-made. Ao ser desviado de seu contexto original e modificado, ele é reconhecido pois "os desvios só são dotados de significado se relacionados às rotas de que foram extraviados" (APPADURAI,2010, p.45). Ou seja, o desvio da subversão necessita sempre do original como referência, a subversão de sentido se dá com o reconheci- 
mento da marca absoluta no seu nome "desviado", mesmo quando se justapõem referências como vemos na (Figura 7).

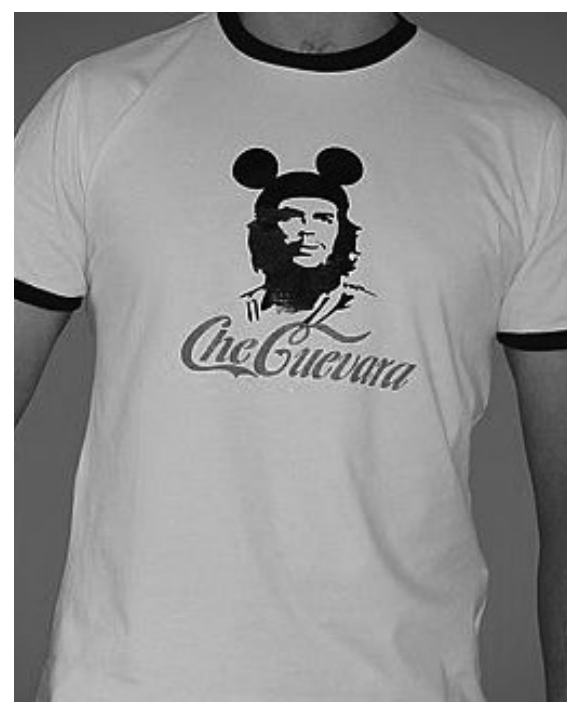

Figura7

Segundo Huizinga (1990) é no mito e no culto que têm origem o direito, o comércio, a indústria, a arte e a ciência. Para esse autor, as grandes atividades arquetípicas são, desde o início, marcadas pelo jogo, que tem características do mito e do culto. A linguagem, também é marcada pelo jogo, pois "brincando com a faculdade de designar é como se o espírito estivesse saltando entre a matéria e as coisas pensadas, pois toda metáfora é jogo de palavras" (HUIZINGA,1990, p.7). O jogo, o riso, a piada, o cômico estão na camada profunda de nosso ser espiritual. A publicidade também “joga” com esses elementos. No começo, a publicidade ensinava como as pessoas deveriam usar os produtos. Eles eram novidade e isso bastava como publicidade. Quando se percebeu que todos os produtos ficaram iguais, e com a incorporação de significado às marcas, o humor passa a ser uma estratégia de diferenciação e a publicidade passa a revelar um tom humorístico (KLEIN, 2002). Com o nonsense e a piada, a publicidade quer somente que o produto apareça num ambiente positivo, para posicionar e construir a imagem da marca. A subversão de sentido em marcas absolutas, além da denúncia, tem também características de jogo. Percebemos um cinismo sobre o cinismo da publicidade, um tipo de contrapropaganda feita com os mesmos elementos visuais e textuais que a publicidade utiliza. É a subversão atuando com as mesmas estratégias da publicidade. (Figuras 8 e 9). 


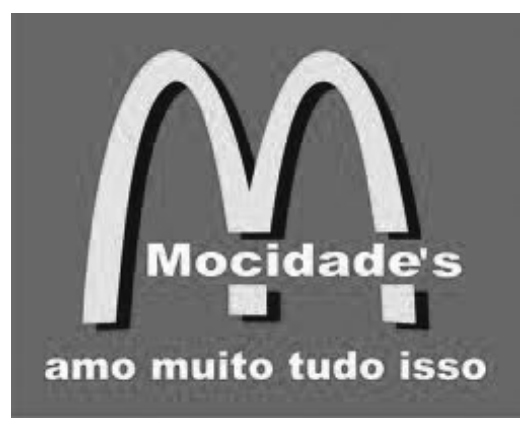

Figura 8

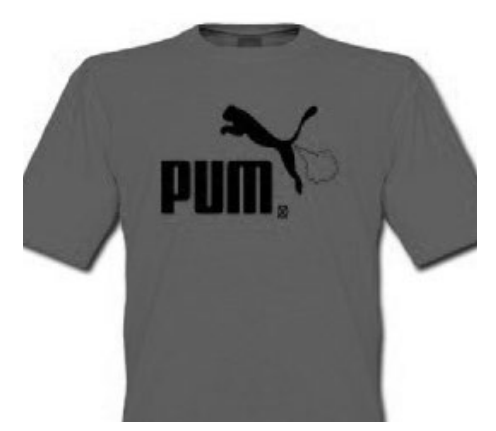

Figura 9

Ou seja: quando lemos Mocidade e não MacDonalds ou quando vemos Pum e não Puma, quando o significante é pouco modificado e apenas uma letra é modificada, percebe-se uma pequena mudança, que traz um significado completamente diferente. É justamente a partir do jogo de palavras e do humor que a conotação possibilita, que a subversão leva a pensar em outros significado e, ao mesmo tempo, tendo a marca como referência. Aí está o jogo.

\section{CONSIDERAÇÕES FINAIS}

O significado de muitos objetos que nos cercam adveio da imagem de marca projetada pela publicidade. Subvertendo essas marcas absolutas pode-se perceber como se dá a produção dos sentidos, que são polissêmicos. Tanto a ideia dessa polissemia, em que os consumidores têm uma liberdade de interpretar e usar os significados, quanto a ideia de luta em torno dos signos foram aqui debatidos. Como ressalta Hall (2003), as coisas são um campo de bataIha do significado, nele, contestamos, invertemos e nos apropriamos deles, de acordo com nossas práticas sociais.

A marca com sentido subvertido tem a marca absoluta como referente. Ela é decodificada, e ressignificada em sua conotação, em seu lugar é produzido um novo signo, portanto, signos "brigando" com signos.

A t-shirts é uma materialidade onde mensagens de contestação têm espaço desde os anos 60. As marcas "invadiram" essa "mídia" para serem usadas como objetos de distinção. A subversão de marcas trava sua "batalha" nesse espaço. Com o jogo e o humor evidencia o mecanismo de significação dos objetos, e de como as marcas atuam como elementos de distinção e status, e ao mesmo tempo enviando mensagens de seus portadores. A mensagem subvertida é feita com as mesmas técnicas utilizadas pela publicidade para o 
desenvolvimento da personalidade do produto. A subversão de sentido é um ready-made de marcas. Sendo elemento do repertório do público, são deslocadas para formar uma nova mensagem, com elementos de humor, jogo e até mesmo denúncia.

A análise de signos subvertidos em camisas revela, sobretudo, a função do nome dentro da marca e do mundo das imagens. O mito da marca é desvendado quando ele destoa pela sintaxe do ready-made. E destoa, na dimensão mais ideológica da linguagem, a conotação.

Segundo Rocha(1995), no clima humano da publicidade se dá a ideologia do esquecimento, o esquecimento do processo por que passou o produto. Como se sua existência anterior fosse pagã e passa ao convívio humano, com a magia da publicidade. As camisas com marcas ressignificadas podem trazer uma reflexão sobre o consumo de imagens de marca, ao lembrarem, com seu conteúdo denunciativo, criativo e bem humorado, o universo da produção e suas contradições, sinalizando que pode não haver um esquecimento, justamente porque os produtos e seus nomes, identidades e personalidades foram colocados no convívio humano. Portanto, as "letras falantes" das marcas, e seus sentidos, têm muito a dizer: é só ler na minha camisa.

\section{REFERÊNCIAS}

APPADURAI, Arjun. “Introdução: mercadorias e política de valor” In A vida social das coisas. Niteroi: UFF, 2010.

BAITELLO, Norval. A serpente, a maçã e o holograma: esboços para uma teoria da mídia. São Paulo: Paulus, 2010.

BAUDOT, François. Moda do século. São Paulo: Cosac \& Naify, 2002.

BAUDRILLARD, Jean El Sistema de los Objetos México. SigloXXI, 1969.

BENJAMIN, Walter. "A obra de arte na era de sua reprodutibilidade técnica". In Obras escoIhidas: magia e técnica, arte e política. São Paulo: Brasiliense, 1985.

CARRASCOZA, João. Redação publicitária-Estudos sobre a retórica do consumo. SP:Futura,2003.

CARRASCOZA, João. Do caos à criação publicitaria. São Paulo:Saraiva,2008.

CANCLINI, Nestor. Consumidores e Cidadãos. Rio de Janeiro: UFRJ, 1999

CANCLINI, Nestor. Leitores, Espectadores, Internautas. São Paulo: Iluminuras, 2008 
CHETOCHINE, G. A derrota das marcas : como evitá-la? São Paulo: Makron Books. 1999 CHEVALIER, Michel Pró-logo - Marcas como fator de progresso. São Paulo: Panda Books. 2007

COHN,Gabriel.“A análise estrutural da mensagem”In Comunicação e indústria cultural SP:Queiroz, 1987.

DRUMMOND DE ANDRADE, Carlos. O Corpo. Rio de Janeiro: Ed. Record,1984

DOUGLAS, Mary e ISHERWOOD, Baron. O Mundo dos Bens. Rio de Janeiro: Editora UFRJ, 2006

FONTELELLE, Isleide. O Nome da Marca. São Paulo: Boitempo Editorial, 2002.

GUMBRECHT, Hans Ulrich. “É apenas um jogo”. In: Corpo e Forma. Rio de Janeiro: EDUERJ, 1998.

HALL, Stuart. “Codificação/Decodificação”. In Da diáspora. SOVIK, Liv BH: Ed. UFMG, 2003.

HUIZINGA, Johan. Homo Ludens. São Paulo: Perspectiva,1990.

KLEIN, Naomi. Sem Logo. São Paulo: Record, 2002

MCLUHAN, Marshall. Os meios de comunicação como extensões do homem. São Paulo: Cultrix, 1995.

NUNES, Mônica R F. "Passagens, paragens, veredas: semiótica da cultura e estudos culturais. In: SANCHES, Tatiana (org.). Estudos culturais: uma abordagem prática. SP: Senac, 2011.

ORTIZ, Renato. Mundialização e Cultura. São Paulo, Brasiliense, 1994

ROCHA, Everardo. Magia e Capitalismo. São Paulo: Brasiliense, 1995

RODRIGUES, Delano Naming - O nome da marca. Rio de Janeiro:2AB, 2011

SLATER, Don. Cultura do Consumo e Modernidade. São Paulo: Nobel, 2002.

RECEBIDO EM: 23/05/2013

ACEITO PARA PUBLICAÇÃO: 28/06/2013 


\title{
Irene Carballido
}

\begin{abstract}
Mestranda em Comunicação e Consumo PPGCOM- ESPM -SP. Membro do GP - "Comunicação, Discursos e Poéticas do Consumo" da ESPM-SP. Bolsista Capes/Prosup. Especialização em Psicocriatividade - Universidad Autónoma de Barcelona. Graduações em Publicidade - Universidade Católica e em Ciências Sociais - UFBA. Redatora publicitária e professora.
\end{abstract}

